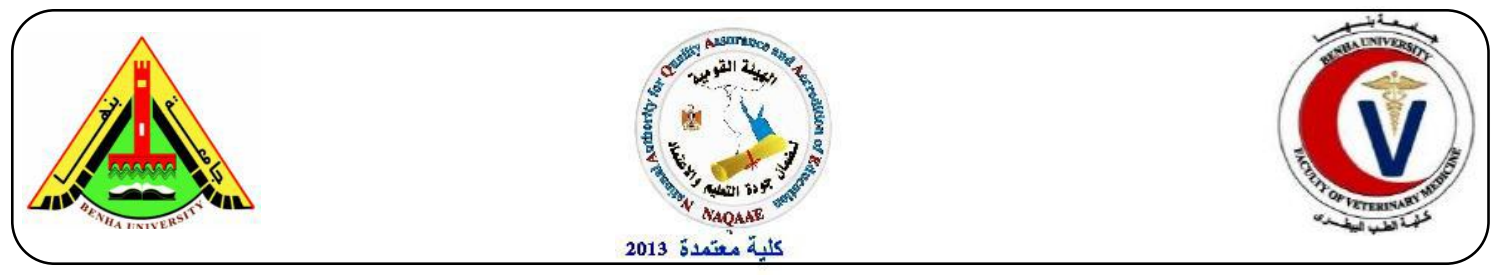

\title{
Genotypic characterization of Brucella Spp. isolated from sheep and goats
}

Ashraf A. Abdeltawab ${ }^{1}$, Mohsen A. Agag ${ }^{2}$, Mahmoud E. Hamdy 3 , Gamal Wareth $^{4,5}$, Fatma I. El-Hofy ${ }^{1}$, Mohamed M. Ramadan ${ }^{1}$

1- Dept. of bacteriology, Immunology and Mycology Benha Univ.

2- Dept. of Theriogenology Benha Univ.

3- Animal Health Institute, Dokki, Giza.

4- Dept. of Pathology Benha Univ.

5- Friedrich-Loeffler-Institut, Institute of Bacterial Infections and Zoonoses, Jena, Germany.

\section{ABSTRACT}

Brucellosis is a major infectious zoonotic disease affecting animal and human. In animal, the disease is causing great economic losses such as abortion, still birth as well as infertility in both male and female. A cross sectional study carried out from November 2016 to May 2017 to estimate the seroprevalence of brucellosis in sheep and goats in Benha. A total of 38 animals (20 sheep, 18 goats) were investigated. 19 serum samples (8 from sheep and 11 from goats) subjected for serological examination. The results showed that, $5 / 8(62.5 \%)$ and $9 / 11(81.8 \%)$ from sheep and goats, respectively, were positive by Rose Bengal Plat test (RBPT), Buffered Acidified Plat Antigen test (BABA) and Rivanol test (RIV test). A total of 34 lymph nodes from seropositive sheep and goats were examined bacteriologically. $3 / 20$ (15\%) and 4/14 (28.57\%) were culture positive for Brucella respectively. None of vaginal swabs revealed culture positive results. All isolates were confirmed genetically as Brucella spp. by PCR and all strains identified as B. melitensis by AMOS- PCR.

Key words: Brucella spp., PCR, AMOS-PCR, sheep and goats

(http://www.bvmj.bu.edu.eg)

(bvmj, 35(1): 22-29, SEPT., 2018

\section{INTRODUCTION}

Brucellosis is one of the most common infectious zoonotic diseases affecting animal and human. The disease caused by member of the Genus Brucella (B). It is known by many different names, remitting fever, undulant fever, Mediterranean fever, Maltese fever, Gibraltar fever, Crimean fever, goat 
fever, and Bang disease (Xavier et al., (2009). It was discovered from 1887 by David Bruce that isolate Brucella melitensis (Micrococcus melitensis) at that time from the spleen of a British soldier who died from a febrile illness (Malta fever) among military personnel stationed on Malta. For almost 20 years after isolation of Micrococcus melitensis, Malta fever remained a mystery and was thought to be a vector-borne disease until Themistocles Zammit accidentally demonstrated the zoonotic nature of the disease in 1905 by isolating B. melitensis from goat's milk (Wyatt. (2005). The genus of Brucella is group of Gram negative facultative intra-cellular, nonmotil, non-sporulated and noncapsulated bacteria. The Genus encompasses 12 accepted nomo-species based on host specificity and biochemical activities (Godfroid et al., (2011). The six classical species are $B$. abortus biovar 1-6 and 9, B. melitensis biovar1-3, B. suis biovar 1-5, B. ovis, B. neotomae which was isolated from wood rats (Morgan, 1984). Four new species described recently, two are of marine origin (B. pinnipedialis and B. ceti). B. microti isolated from the common vole Microtus arrivals (Scholz et al., (2008), Finally, in 2016, B. vulpis sp. nov., isolated from mandibular lymph nodes of red foxes (Vulpes vulpes) (Scholz et al., (2016). B. inoponata isolated from breast implant wound of a female patient (Scholzet al., 2010). There is only 4 species of Brucella from all species have zoonotic importance. B. melitensis (from sheep; highest pathogenicity), B. suis (from pigs high pathogenicity), B.abortus (from cattle; moderate pathogenicity), B. canis (from dogs; moderate pathogenicity). B. melitensis considered the most frequently reason for human sickness as it is the most virulent species and connected with serious acute illness (Yagupsky. (1999).

Brucellosis in sheep and goat caused by $B$. melitensis which affecting sheep and goat, B. ovis which affecting only sheep, B. suis biovar 5 (Scholz et al., (2008). Brucellosis causes great economic losses in livestock industry as it provokes abortions, retained placenta and decreased milk production in females, while provokes orchitis and sterility in males, in addition to veterinary care in sheep and goat as well as treatment costs in human (Adams. (2002) .

Brucellosis was first reported in Egypt in 1939, however there is high prevalence rates of $B$. melitensis infections in sheep and goats, $B$. melitensis infections of cattle and buffaloes have increased in Egypt due to mixed populations of sheep, goats, cattle, and buffaloes Refai. (2002)

So the aim of this study was to estimate the seroprevalence of Brucella spp. in sheep and goats in Benha governorate in Egypt, and to identify Brucella spp. by bacteriological culturing and AMOS- PCR.

\section{MATERIAL AND METHODS}

\subsection{Samples:}

The study carried out on 57 samples (34 lymph node, 19 serum and 4 vaginal 
swabs) from38 animals (20 sheep, and 18 goats) from different localities in Egypt during the period from Nov. 2016 to May 2017 (Table 1). The samples were transferred to the lab in ice bags as quick as possible to make identification of samples.

\subsection{Serum examination:}

Serum samples collected from the animals (sheep and goats) then examined using the Buffered Acidified Plate Antigen (BAPA) test, the Rose Bengal Plate test (RBPT), and the Rivanol test (Alton et al., (1988; Refai. (2002),

The serological tests recommended by the National Brucella Committee, by veterinary laboratories, and universities in Egypt. Serum samples were considered positive when they tested positive for at least two serological tests.

\subsection{Brucella spp. isolation:}

Direct culturing of lymph nodes and vaginal swabs on selective Brucella agar was done and plates were incubated at $37^{\circ} \mathrm{C}$ with $5 \% \mathrm{CO}_{2}$. Media were routinely examined on the $4^{\text {th }}$ day and upwards every 48 hours before being discarded as negative after 3 weeks, the suspected colonies were further identified and sub-cultured on Brucella agar and the colonies identified when plates were held up towards indirect daylight and viewed through the Brucella agar media as previously described (Alton et al., (1988).

\subsection{Biochemical identification:}

The isolates were typed according to $\mathrm{CO}_{2}$ requirement, $\mathrm{H}_{2} \mathrm{~S}$ production,
Oxidase, Catalase, Urease tests and Gram reaction according to Alton et al., (1988)

\subsection{Application of $c P C R$ and AMOS} $P C R$ :

The brucellae isolates were subjected to DNA extraction, DNA was extracted using the QIAamp DNA Mini Kit (catalogue number51306) according to the manufacturer's guidelines. Brucella species were identified from the extracted DNA by multiplex PCR according to Alton et al., (1988).

AMOS PCR: AMOS-PCR was performed at the OIE/NRL for brucellosis at Friedrich-Loeffler-Institut, Federal Research Institute for Animal Health, Institute of Bacterial Infections and Zoonoses, Jena, Germany. Following inactivation of bacteria at $80^{\circ} \mathrm{C}$ for 2 hours. DNA was extracted with the high pure PCR template preparation kit (Roche Applied Sciences, Mannheim, Germany) according to the manufacture instructions. The AMOS PCR (B. abortus, B. melitensis, B.ovis and $B$. suis PCR) was performed as described before (Bricker and Halling, 1994). The oligonucleotide primers used in this study shown in table (3).

\section{RESULTS}

3.1. Detection and Seroprevalence of Brucella spp. in sheep and goats: As shown in table 2, five samples showed sero-positive reaction from eight serum samples collected from sheep and nine were sero-positives from 11 serum sample collected from goat. 


\subsection{Identification of Brucella:}

The result of Brucella isolation revealed that the total number of isolates (7) (3 isolates from sheep and 4 isolates from goat) were suspected to be Brucella. The colonial morphology were round, $1-2 \mathrm{~mm}$. in diameter, with smooth margins, round edges, translucent and of golden colour (pale honey-colored). When viewed from above, colonies were convex, on Brucella agar, Brucella selective media and Blood agar (Fig.1)

The microscopical examination of isolates showed Gram negative coco bacilli.

-Biochemically, all isolates were positive catalase and oxidase, Urease, $\mathrm{H}_{2} \mathrm{~S}$ test.

1- Positive result of Catalase test air bubbles appear on plate.

2- Positive results of Oxidase test appear change color of Oxidase paper to blake or dark color

3- Positive result of Urease test appears from $5 \mathrm{~min}$ to $30 \mathrm{~min}$ as change of suspension color to rose color. After $2 \mathrm{hr}$ consider negative result

4- Positive result of $\mathrm{H}_{2} \mathrm{~S}$ changes color of $\mathrm{H}_{2} \mathrm{~S}$ paper to black.

\section{3. $P C R$ results:}

All examined isolates were positive and showed clear band at $223 \mathrm{bp}$ for Brucella spp by Conventional PCR.

AMOS-PCR confirmed that all Brucella isolates were B. melitensis at $730 \mathrm{bp}$.

Table (1): Types of samples from sheep and goat

\begin{tabular}{lllll}
\hline Samples & No. of animal & $\begin{array}{l}\text { No. of Serum } \\
\text { samples }\end{array}$ & $\begin{array}{l}\text { No. of Lymph } \\
\text { node }\end{array}$ & $\begin{array}{l}\text { No. of } \\
\text { Vaginal swab }\end{array}$ \\
\hline Sheep & 20 & 8 & 20 & - \\
Goat & 18 & 11 & 14 & 4 \\
\hline Total & 38 & 19 & 34 & 4 \\
\hline
\end{tabular}

Table (2) :Seroprevalence of Brucella spp.in sheep and goats.

\begin{tabular}{|c|c|c|c|c|c|c|c|}
\hline \multirow[t]{2}{*}{ Animals } & \multirow{2}{*}{$\begin{array}{l}\text { No .of } \\
\text { serum } \\
\text { sample }\end{array}$} & \multicolumn{2}{|l|}{ RBPT } & \multicolumn{2}{|l|}{ BABT } & \multicolumn{2}{|l|}{ RIV. Test } \\
\hline & & $\begin{array}{l}\text { No .os } \\
\text { positive } \\
\text { sample }\end{array}$ & $\%$ & $\begin{array}{l}\text { No .os } \\
\text { positive } \\
\text { sample }\end{array}$ & $\%$ & $\begin{array}{l}\text { No .os } \\
\text { positive } \\
\text { sample }\end{array}$ & $\%$ \\
\hline Sheep & 8 & 5 & $62.5 \%$ & 5 & $62.5 \%$ & 5 & $62.5 \%$ \\
\hline
\end{tabular}




\begin{tabular}{llllllll}
\hline Goats & 11 & 9 & $81.8 \%$ & 9 & $81.8 \%$ & 9 & $81.8 \%$
\end{tabular}

Table (3), Specific primers for AMOS PCR

\begin{tabular}{ccc}
\hline Primer & Nucleotide sequence 5'-3 & Base pair \\
\hline B.melitensis & AAA-TCG-CGT-CCT-TGC-TGG-TCT-GA & 495 \\
B.abortus & GAC-GAA-CGG-AAT-TTT-TCC-AAT-CCC & 730 \\
IS711 & TGC-CGA-TCA-CTT-AAG-GGC-CTT-CAT & \\
\hline
\end{tabular}

Figure (1) morphological appearancê of Brucella on Brucella agar.

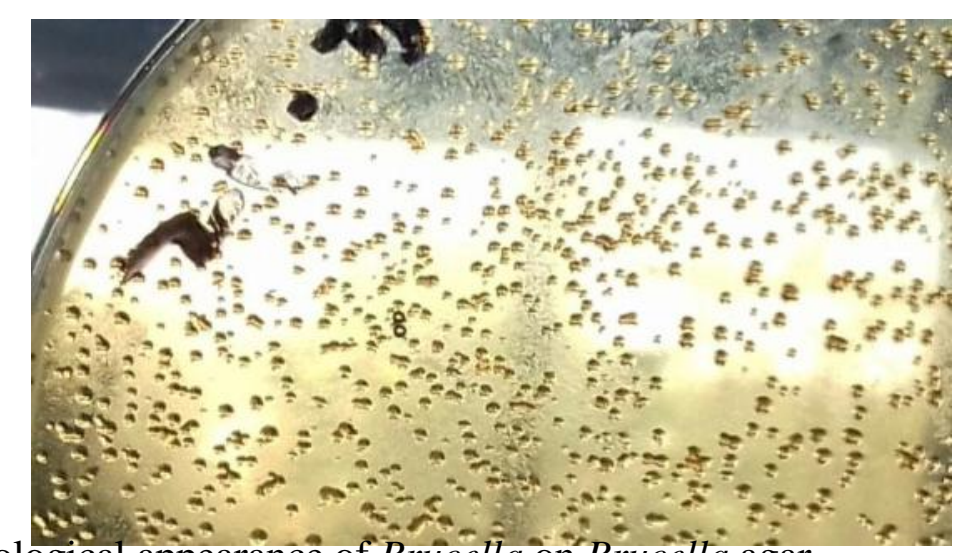

\section{DISCUSSION:}

Brucellosis considered one of a serious infectious zoonotic disease which affecting animal and human caused by genus Brucella which is Gram negative, non-motile, non-sporulated, facultative intracellular coco bacilli capable of invading epithelial cells, placental trophoblasts, dendritic cells, and macrophages Gorvel. (2008)

The current results for Brucella serodiagnosis showed that $5 / 8(62.5 \%)$ and $9 / 11(81.8 \%)$ from sheep and goats respectively were positive by Rose
Bengal Plat test(RBPT), Buffered Acidified Plat Antigen test (BABA) and Rivanol test (RIV test). These results were agreed with Samar (2014) who reported that $61.81 \%$ from sheep and $73.3 \%$ from goat were positive by (BAPT), but by using (RBPT) and (TAT), $61.81 \%$ from sheep and $66.66 \%$ from goat were positive. Finally, by (CFT) there is $60.0 \%$ from sheep and $66.66 \%$ from goats were positive. While these results disagreed with Ammar. (2000) who revealed that, the rate of Brucella infection was markedly higher among goats (3.49\%) using BAPAT than among sheep (2.58\% using BAPAT)and 
Rahman et al., (2011) who showed that percentage of positive reactors among goats $(4.72 \%)$ while among sheep $(3.08 \%)$. Also they found that the positive reactors are relatively higher in females $(4.04 \%)$ than in males $(0.0 \%)$ in goats and $(2.6 \%)$ in females, $(0.0 \%)$ in males in sheep by using RBPT. Due to they make serodiagnosis in different area and breeds so that rate of infection was differed from our results.

The current results of Brucella isolation in this study were $3 / 20$ (15\%) and 4/14 (28.57\%) for Brucella in sheep and goat respectively. The vaginal swabs were $0.0 \%$ for Brucella.

These results agreed with Kaoud et al., (2010). The results pointed out that, prevalence of brucellosis among herds/flocks of sheep, goats and cattle were; $26.66 \%, 18.88 \%$ and $17.22 \%$ respectively. While differed with the results of Affi et al., (2011) who showed that Brucella sp. was isolated from different lymph nodes and spleen tissues was of $9(28.13 \%)$ out of 32 in cattle, 25 $(36.23 \%)$ out of 69 in sheep and of 5 $(100 \%)$ out of 5 in goats, while the overall rate of isolation was $36.8 \%$ of the total number of examined animals.

These present results were confirmed by Conventional PCR and further identified by AMOS-PCR. All isolates were confirmed genetically as Brucella spp. by CPCR and all strains identified as $B$. melitensis by AMOS- PCR, where Wareth et al., (2014) stated that AMOS PCR is accurate method for differentiation of Brucella spp.
In Conclusion Brucellosis causing great economic losses among sheep and goats as it cause abortion in late stage of pregnancy, still birth and infertility in both male and female. The current results revealed that $B$. melitensis plays a big role in reproductive problems in sheep and goats. Serological techniques considered the basic test for farm diagnosis in the current study and AMOS-PCR is most accurate, specific, fast and sensitive test for differentiation between Brucella spp.

\section{Acknowledgment}

We would like to thank The Academy of Scientific Research \& Technology (ASRT) for financial support. This work is belonging to project (ID_698_BrucMedNet) funded through the ARIMNet2-2015 Call. We would like to thank OIE/NRL for brucellosis at Friedrich-Loeffler-Institut, Federal Research Institute for Animal Health, Institute of Bacterial Infections and Zoonoses, Jena, Germany for scientific support.

\section{REFERENCES}

Adams, L.G., (2002): The pathology of brucellosis reflects the outcome of the battle between the host genome and the Brucella genome. Veterinary microbiology 90, 553561.

Affi, M.; Abdul-Raouf, U.; El-Bayoumy, E.; Montasser, A.and Mohamad, H., (2011): Isolation and biotyping of Brucella melitensis from Upper 
Egypt. Journal of American Science 7, 653-659.

Alton, G.; Jones, L.; Angus, R.and Verger, J., (1988): Bacteriological methods. Techniques for the brucellosis laboratory, 13-61.

Ammar, K., (2000): Some epidemiological aspects of bovine, ovine and caprine brucellosis in Egypt Suez Canal Vet. Med. J.(SCVMJ) 3, 145-156.

Bricker, B., Halling, S., 1994.

Differentiation of Brucella abortus bv. 1, 2, and 4, Brucella melitensis, Brucella ovis, and Brucella suis bv. 1 by PCR. . Journal of clinical microbiology 32, 2660-2666.

Godfroid, J.; Scholz, H.; Barbier, T.; Nicolas, C.; Wattiau, P.; Fretin, D.; Whatmore, A.; Cloeckaert, A.; Blasco, J.and Moriyon, I., (2011): Brucellosis at the animal/ecosystem/human interface at the beginning of the 21st century. Preventive veterinary medicine 102, 118-131.

Gorvel, J.-P., (2008): Brucella: a Mr "Hide" converted into Dr Jekyll. Microbes and infection 10, 10101013.

Kaoud, H.; Zaki, M.M.; El-Dahshan, A.and Nasr, S.A., (2010): Epidemiology of brucellosis among farm animals. Nature and science 8, 190-197.

Rahman, M.; Faruk, M.; Her, M.; Kim, J.; Kang, S.and Jung, S., (2011): Prevalence of brucellosis in ruminants in Bangladesh. Veterinarni Medicina 56, 379-385.

Refai, M., (2002): Incidence and control of brucellosis in the Near East region. Veterinary microbiology 90, 81-110.

Scholz, H.C.; Al Dahouk, S.; Tomaso, H.; Neubauer, H.; Witte, A.; Schloter, M.; Kämpfer, P.; Falsen, E.; Pfeffer, M.and Engel, M., (2008): Genetic diversity and phylogenetic relationships of bacteria belonging to the Ochrobactrum-Brucella group by recA and 16S rRNA gene-based comparative sequence analysis. Systematic and applied microbiology 31, 1-16.

Scholz, H.C.; Revilla-Fernandez, S.; Al Dahouk, S.; Hammerl, J.A.; Zygmunt, M.S.; Cloeckaert, A.; Koylass, M.; Whatmore, A.M.; Blom, J.; Vergnaud, G.; Witte, A.; Aistleitner, K.and Hofer, E., (2016): Brucella vulpis sp. nov., isolated from mandibular lymph nodes of red foxes (Vulpes vulpes). International journal of systematic and evolutionary microbiology 66, 2090-2098. 
Wareth, G.; Hikal, A.; Refai, M.; Melzer, F.; Roesler, U.and Neubauer, H., (2014): Animal brucellosis in Egypt. The Journal of Infection in Developing Countries 8, 1365-1373.

Wyatt, H., (2005): How Themistocles Zammit found Malta Fever (brucellosis) to be transmitted by the milk of goats. Journal of the Royal Society of Medicine 98, $451-454$.
Xavier, M.; Paixão, T.; Poester, F.; Lage, A.and Santos, R., (2009): Pathological, immunohistochemical and bacteriological study of tissues and milk of cows and fetuses experimentally infected with Brucella abortus. Journal of comparative pathology 140, 149157.

Yagupsky, P., (1999): Detection of Brucellae in blood cultures. Journal of clinical microbiology 37, 3437-3442. 